\title{
Dispersão zoocórica e hidrocórica marítima de Opuntia monacantha (Willd.) Haw. (Cactaceae)
}

\author{
Maurício Lenzi ${ }^{1,3 *}$ \\ Maurício Eduardo Graipel² \\ Josy Zarur de Matos $^{3}$ \\ Angelo Martins Fraga ${ }^{4}$ \\ Afonso Inácio Orth ${ }^{1}$ \\ 'PPG em Recursos Genéticos Vegetais, Centro de Ciências Agrárias \\ Universidade Federal de Santa Catarina, Rodovia Admar Gonzaga, 1346 \\ CEP 88034-001, Florianópolis - SC, Brasil \\ ${ }^{2}$ Centro de Ciências Biológicas, Universidade Federal de Santa Catarina, Florianópolis - SC, Brasil \\ ${ }^{3}$ Instituto Iberoamericano de la Biodiversidad - CIBIO, Universidad de Alicante \\ Carretera San Vicente del Raspeig, s/n, 03690, San Vicente, España \\ ${ }^{4}$ PPG em Geografia, Universidade Federal de Santa Catarina, Florianópolis - SC, Brasil \\ *Autor para correspondência \\ mlenzi34@hotmail.com
}

Submetido em 25/05/2011

Aceito para publicação em 01/12/2011

\section{Resumo}

Adaptações evolutivas na morfologia e fisiologia das cactáceas têm sido associadas aos seus mecanismos de dispersão e colonização. Os mecanismos e modos de dispersão de Opuntia monacantha (Willd.) Haw. (Cactaceae) foram caracterizados em duas praias de Florianópolis, SC, Brasil. Um marsupial do gênero Didelphis (Mammalia: Didelphidae) foi o único frugívoro e, portanto, dispersor de frutos, apresentando locais específicos para alimentação. A hidrocoria marítima ocorreu após a invasão marinha sobre a vegetação de restinga, caracterizando-se pela dispersão de cladódios e frutos em várias épocas do ano. Descreve-se pela primeira vez a ação do mar como potencial dispersor para uma espécie de cactos.

Palavras-chave: Cactos, Didelphis, Frugivoria, Invasão marinha, Restinga

\section{Abstract}

Zoochoric and hydrochoric maritime dispersal of the Opuntia monacantha (Willd.) Haw. (Cactaceae). Evolutionary adaptations in the morphology and physiology of cactus species have been associated to their mechanisms of dispersal and colonization. The dispersal mechanisms and modes of Opuntia monacantha (Willd.) Haw. (Cactaceae) were characterized in two beaches in Florianopolis, SC, Brazil. A marsupial from the genus Didelphis (Mammalia: Didelphidae) was the only frugivorous and, thus, disperser of fruits, presenting specific eating places. The maritime hydrochory was due to the overwash on restinga vegetation, it is characterized by the dispersal of cladodes and fruits at various times of the year. It is here firstly described the sea action as a potential disperser for a cactus species.

Key words: Cactus, Didelphis, Frugivory, Overwash, Restinga 


\section{Introdução}

Restinga é o termo utilizado para caracterizar os depósitos marinhos litorâneos e depósitos de material continental, formados durante as regressões e transgressões marinhas (ARAÚJO; LACERDA, 1987; SUGUIO, 2003), comumente denominados de planícies litorâneas. O termo restinga também vem sendo empregado para designar os diversos tipos de formações vegetacionais que ocorrem sobre as planícies litorâneas, como as comunidades de praias, de ante-dunas, de cordões arenosos, de depressões entre cordões arenosos e de margens de lagoas (ARAÚJO; LACERDA, 1987).

As restingas são representadas nas regiões Sudeste e Sul pelos estratos herbáceo, arbustivo e florestal, cujas diferenças ocorrem, basicamente, em função da proximidade do mar ou do distanciamento deste em direção ao interior do continente, e das características físicas e hidrológicas do substrato (KLEIN, 1961; ARAÚJO, 1992). Por sua vez, essas diferentes comunidades vegetacionais originam uma grande heterogeneidade de ambientes, propiciando a formação de áreas com elevada diversidade ecológica (FALKENBERG, 1999; KLEIN et al., 2007). De forma que, para Falkenberg (1999), as restingas devem ser compreendidas em um sentido mais amplo, como ecossistema, considerando não só as comunidades de plantas, mas também a de animais e o ambiente físico em que vivem.

Opuntia monacantha (Willd.) Haw. é um cacto litorâneo, herbáceo, colonizador da vegetação de restinga, que habita as dunas fixas, semifixas e costões rochosos mais próximos da faixa da praia (SCHEINVAR, 1985). De acordo com LENZI (2008), seu caule é modificado em cladódios, estruturas em forma de palma, envolvidas na reprodução, propagação e dispersão destas plantas. As aréolas presentes nos cladódios possuem alta capacidade de diferenciação meristemática, podendo gerar raízes, brotos e flores. $O$ fruto carnáceo é revestido por tecido de caule, apresentando as mesmas características reprodutivas dos cladódios, possuindo em seu interior polpa nutritiva com aproximadamente uma centena de sementes férteis (LENZI, 2008).

Existem muitos fatores que atuam na determinação dos padrões de dispersão das plantas e neste processo, os frugívoros são um elemento importante, contribuindo nos estágios sucessionais e na manutenção da heterogeneidade de diversos hábitats (DOMÍNGUEZ-DOMÍNGUEZ et al., 2006). O papel dos frugívoros na dispersão de cactos da Mata Atlântica é relatado para aves (SILVA, 1988; PEDRONI; SANCHES, 1997; SCHERER et al., 2007), macacos (PEDRONI; SANCHES, 1997), lagartos (CASTRO; GALETTI, 2004) e morcegos (ZORTÉA; CHIARELLO, 1994; SATO et al., 2008). Na Ilha de Santa Catarina, alguns mamíferos têm sido apontados como frugívoros dispersores de várias espécies vegetais, dentre eles o marsupial Didelphis aurita (Wied-Newied, 1826) (Mammalia: Didelphimorphia, Didelphidae) (CACERES et al., 2002; 2009), também conhecido como gambá-de-orelha-preta (GRAIPEL et al., 2001).

A ação da invasão marinha ("overwash") nos setores de duna frontal, locais mais sujeitos à ação marinha, pode afetar o desenvolvimento e a permanência das populações de plantas presentes nessas áreas, interferindo diretamente na sua dinâmica de colonização (KEDDY, 1982). Por outro lado, frutos e sementes de espécies que possuem tolerância à água, à alta salinidade e ao soterramento podem se beneficiar (CASTELLANI; SANTOS, 2005).

O objetivo principal deste trabalho é o de identificar e caracterizar os padrões e mecanismos de dispersão dos cladódios e frutos de $O$. monacantha em restinga de duas praias do município de Florianópolis, estado de Santa Catarina.

\section{Material e Métodos}

O estudo foi realizado em região costeira com vegetação de restinga e na faixa de praia. As áreas estudadas estão localizadas na praia da Galheta (área 1), Parque Municipal da Galheta, costa Leste $\left(27^{\circ} 35^{\prime} 28^{\prime}\right.$ 'S e 48 25'26”O) e na praia da Armação (área 2), Parque Municipal da Lagoa do Peri, costa Sul $\left(27^{\circ} 44^{\prime} 38^{\prime \prime}\right.$ S e 48³0’32”O) (Figura 1).

O tipo de vegetação presente nas áreas estudadas é o de restinga herbáceo-arbustiva que, segundo Falkenberg (1999), está distribuída ao longo de três fisionomias marcantes: i) praias e dunas frontais; ii) dunas internas e 
planícies; e iii) lagunas, banhados e baixadas. O estrato herbáceo é caracterizado principalmente por plantas de pequeno porte sujeitas a uma maior influência luminosa e marinha, compreendendo os agrupamentos vegetais mais próximos do mar; o estrato arbustivo apresenta espécies de maior porte, que possuem entre 1 a $5 \mathrm{~m}$ de altura (FALKENBERG, 1999).

FIGURA 1: Mapa de localização das áreas de estudo no município de Florianópolis, SC. Adaptado a partir do Mapa Político do estado de Santa Catarina (1997), da Secretaria de Desenvolvimento Econômico e Integração ao Mercosul, e das cartas topográficas, SG-22-Z-D-V-2 (Florianópolis) (IBGE, 1981a) SG22-Z-D-VI-1 (Lagoa) (IBGE, 1981b) e SG-22-ZD-V-4 (Paulo Lopes) (IBGE, 1983).

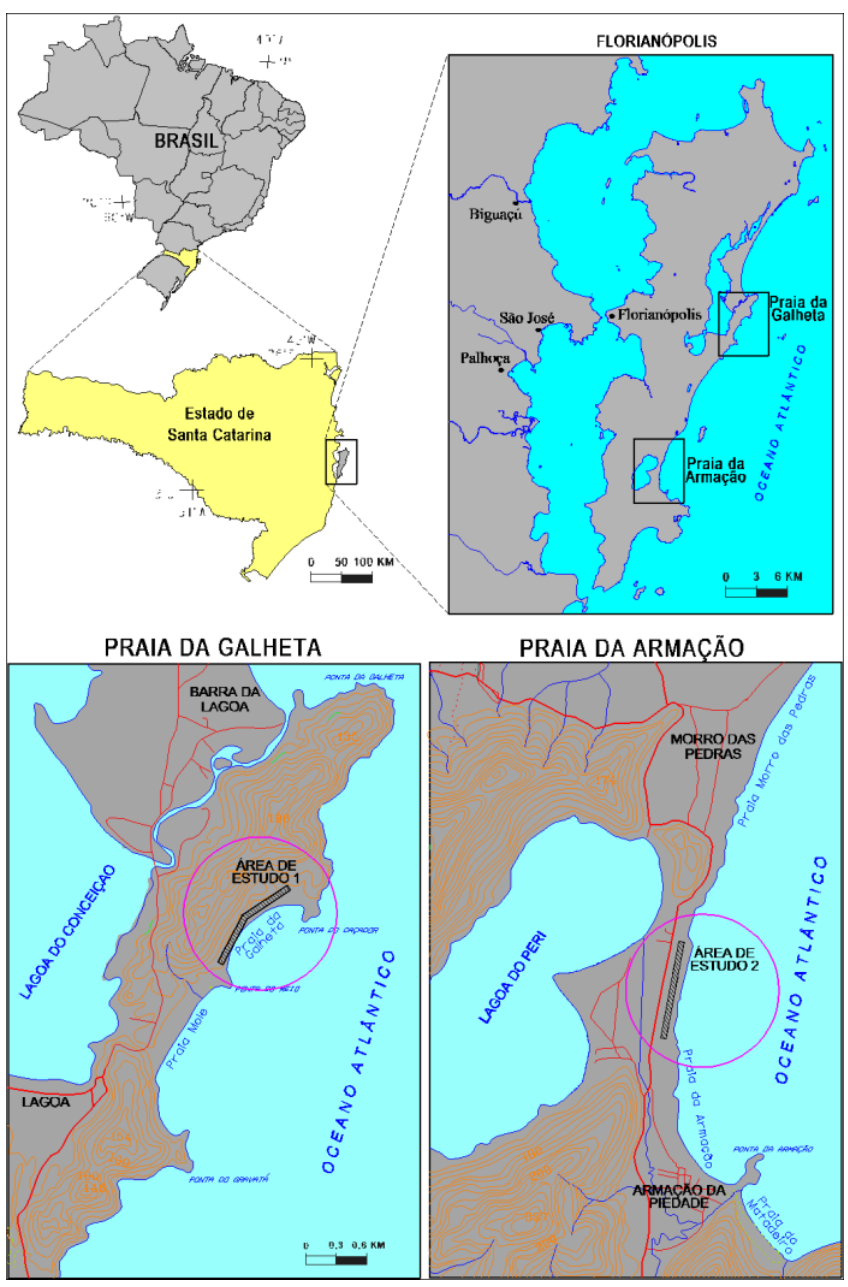

O trabalho no campo foi desenvolvido mensalmente, de janeiro a dezembro de cada ano, durante três anos consecutivos de 2005 a 2007.
A dispersão zoocórica foi acompanhada e avaliada apenas na praia da Armação, durante os anos de 2006 e 2007, em uma área de aproximadamente $1.000 \mathrm{~m}$ de comprimento por $20 \mathrm{~m}$ de largura a partir da faixa da praia. O critério de escolha e delimitação da área de estudo foi o de utilizar um remanescente de vegetação conservada, sem alteração urbana. A dispersão zoocórica foi caracterizada pelo consumo de alguma parte da estrutura do fruto, ou seja, quando tivesse servido de alimento a algum animal.

Os locais onde se encontraram os frutos consumidos tiveram sua área medida $\left(\mathrm{m}^{2}\right)$ e sua posição determinada com o uso de um GPS. Nestes locais, foi observado o estado de conservação dos frutos e se apresentavam enraizamento, brotação e indícios de frugivoria.

Avaliou-se o consumo de frutos $(\mathrm{n}=120)$ na praia da Armação, da seguinte forma: i) identificaram-se 30 frutos maduros com pequenas etiquetas metálicas, em três plantas, a fim de se determinar qual o consumo e a distância que poderiam ser carregados pela espécie dispersora; e ii) frutos maduros $(n=90)$, colhidos de diversas plantas próximas, foram reunidos em número de dez e deixados diretamente sobre o solo em três locais onde já haviam sido encontrados restos de frutos consumidos por algum frugívoro. O registro do consumo foi feito após uma semana do início do experimento.

Em laboratório, foi possível descartar a possibilidade das impressões dentárias deixadas nos frutos de $O$. monacantha pertencerem a outras espécies que não aos gambás, Didelphis spp. Utilizou-se como base a anatomia e estrutura dentária de mamíferos, tendo como referência crânios de espécies registradas para a Ilha de Santa Catarina depositados na Coleção Científica de Mamíferos da Universidade Federal de Santa Catarina - UFSC.

Para testar se as análises morfológicas e de estrutura das arcadas dentárias eram corroboradas por análises biométricas utilizou-se o Teste $t$, para detectar diferenças significativas $(\mathrm{p}>0,05)$. Desta forma, compararam-se as médias das medidas de largura mínima entre perfurações atribuídas aos caninos superiores e caninos inferiores e as médias das medidas da largura mínima na base dos caninos superiores e dos caninos inferiores dos crânios 
(n=18) de D. aurita, tombados na Coleção Científica de Mamíferos da UFSC. Utilizaram-se as medidas de $D$. aurita uma vez que esta é a única espécie conhecida do gênero para a Ilha de Santa Catarina (GRAIPEL et al., 2001).

A caracterização da invasão marinha ("overwash") sobre a vegetação de restinga e da dispersão dos propágulos pela hidrocoria marítima foi realizada na praia da Galheta, em um transecto de 920 x 6m, e na praia da Armação, em um transecto 1.150 x 5m. Os levantamentos foram realizados entre os meses de agosto e novembro de 2005 e julho e dezembro de 2006. Foram avaliados: o período em que ocorre o processo, a distância (metros) da invasão do mar sobre a vegetação de restinga, a distância (metros) das estruturas dispersas (frutos e cladódios) a partir da faixa de praia sobre a vegetação de restinga e o número de propágulos dispersos (frutos e cladódios).

Cladódios $(n=15)$ e frutos $(n=30)$ foram jogados ao mar para detectar se possuíam alguma capacidade de flutuação. Em laboratório, cladódios $(n=5)$ e frutos $(\mathrm{n}=10)$ foram deixados individualmente em recipientes plásticos, com água marinha renovada semanalmente, para se avaliar o tempo de flutuação e da tolerância à imersão na água do mar.

\section{Resultados}

A dispersão zoocórica por gambás foi confirmada pelas análises morfológicas em laboratório e biométricas, as quais não apresentaram diferença significativa entre as médias dos caninos superiores $(t=0,350 ; p=0,723)$ e caninos inferiores $(t=1,028 ; p=0,307)$ de crânios e perfurações nos frutos (Figura 2).

Constatou-se que 15 frutos, $(50 \%)$ do total $(n=$ 30) daqueles etiquetados na plantas, foram removidos e carregados até uma distância de $80 \mathrm{~m}$ dos locais de origem, para locais de alimentação no sub-bosque da vegetação arbustiva.

Os 90 frutos oferecidos sobre o solo, nos locais de alimentação, foram todos remexidos e apresentaram sinais de mordedura, mas não carregados para outros locais. Seu consumo foi alto $(n=89)$, sendo a polpa e as sementes totalmente consumidas e o restante da estrutura (pedicelo) descartada. Na maioria das vezes $(n=81)$ as aréolas presentes nos pedicelos diferenciam-se em raízes e brotos, originando novos clones. Estes locais de alimentação apresentaram centenas de restos de frutos (pedicelos) em diferentes estágios de enraizamento e brotação.

Foram encontrados oito locais de alimentação na área estudada, na praia da Armação, todos no sub-bosque do estrato arbustivo da restinga. Os locais apresentaram uma área média de $66 \pm 14,64 \mathrm{~m}^{2}(\mathrm{n}=8)$ a uma distância máxima de até $30 \mathrm{~m}$ entre si. Embora tenham sido observados frutos consumidos por algum frugívoro na praia da Galheta não foram realizadas coletas nesta área.

FIGURA 2: Semelhanças entre as medidas obtidas dos dentes de gambás e daquelas deixadas por frugívoros em frutos de Opuntia monacantha, em restinga da praia da Armação, SC: média, desvio padrão e max $\geq \min$ das medidas relativas $(\mathrm{mm})$ à largura mínima $(\mathrm{mm})$ nos frutos entre caninos superiores (LFS), largura mínima em gambás entre caninos superiores (LCS), largura mínima nos frutos entre caninos inferiores (LFI) e largura mínima em gambás entre caninos inferiores (LCI).

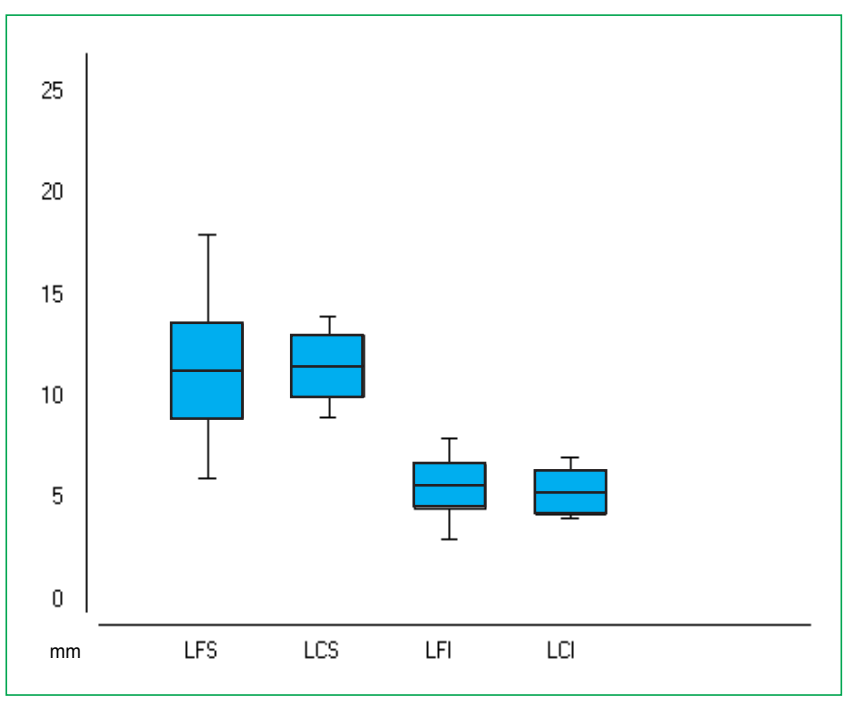

Os 41 cladódios encontrados no lixo de maré foram dispersos até uma distância média de 3,5 $\pm 0,97 \mathrm{~m}$ e os 40 frutos até uma distância média de 4,58 $\pm 0,87 \mathrm{~m}$ (Tabela 1). Em ambos os casos, cladódios e frutos foram trazidos pelas ondas e depositados sobre a faixa de praia, dunas e no estrato herbáceo da restinga. 
Ao longo de 2005 e 2006 foram observadas outras invasões marinhas havendo remoção de cladódios e frutos já em fase de enraizamento e brotação e nova deposição dos mesmos (Tabela 1).

Na praia da Galheta, no mês de novembro de 2005, dos 14 cladódios restantes após a dispersão marítima, constatou-se que $12(85,7 \%)$ emitiram brotos vegetativos e todos emitiram raízes, sendo que apenas um emitiu botão floral. Dos 33 frutos amostrados, no mesmo local e período, constatou-se que $23(69,7 \%)$ emitiram brotos e todos emitiram raízes, não havendo registro da emissão de botões florais. Na praia da Armação, no mesmo período, dos 27 cladódios e sete frutos restantes após a invasão marinha contatou-se, também, que todos emitiram raízes e brotos (Tabela 1).

TABELA 1: Dispersão marítima de estruturas propagativas (cladódios) e reprodutivas (frutos) de Opuntia monacantha avaliados em transectos nas praias da Galheta e Armação, Florianópolis, $\mathrm{SC}$, entre os meses de agosto e novembro do ano de 2005 e julho e dezembro de 2006. Número $(\mathrm{N})$, média $(\mathrm{X})$ em metros $(\mathrm{m}) \mathrm{e}$ desvio padrão (SD) de estruturas encontradas a partir da faixa de praia.

\begin{tabular}{cccccc}
\hline \multicolumn{2}{c}{ Avaliação } & \multicolumn{2}{c}{$\begin{array}{l}\text { Praia da } \\
\text { Galheta }\end{array}$} & \multicolumn{2}{c}{$\begin{array}{c}\text { Praia da } \\
\text { Armação }\end{array}$} \\
\hline Período & Estruturas & N & X m \pm SD & N & X m \pm SD \\
\hline \multirow{2}{*}{ Agosto/05 } & Cladódios & 36 & $2,65 \pm 1,23$ & 43 & $2,40 \pm 1,13$ \\
& Frutos & 132 & $4,50 \pm 1,19$ & 19 & $2,95 \pm 1,26$ \\
Novembro/05 & Cladódios & 14 & $3,5 \pm 0,97$ & 27 & $2,58 \pm 0,98$ \\
& Frutos & 33 & $4,58 \pm 0.87$ & 7 & $3 \pm 0,71$ \\
Julho/06 & Cladódios & 19 & $2,16 \pm 1,10$ & 39 & $2,35 \pm 1,17$ \\
& Frutos & 73 & $3,2 \pm 0,73$ & 22 & $1,98 \pm 0,99$ \\
Dezembro/06 & Cladódios & 6 & $2,5 \pm 0,61$ & 18 & $2,42 \pm 1,22$ \\
& Frutos & 3 & $3,5 \pm 1,42$ & 3 & $2 \pm 1$ \\
\hline
\end{tabular}

Entre julho e dezembro de 2006, o padrão da dispersão dos cladódios e frutos, ocasionados pela invasão marinha foi semelhante. Entretanto, muitos dos cladódios e frutos da dispersão anterior já não se encontravam mais no local. A dispersão ocorrida no ano de 2006 (Tabela 1) foi mais concentrada em uma faixa com menor extensão.
Os cladódios $(n=15)$ e frutos $(n=30)$ possuem boa capacidade de flutuação, pois flutuam quando jogados ao mar e nos recipientes, durante todo o período do experimento, no laboratório. Em relação à imersão em água do mar, somente a partir da segunda semana os cladódios $(n=5)$ e frutos $(n=10)$ começaram a apresentar indícios de necrose e putrefação.

\section{Discussão}

As análises morfológicas e impressões das presas (caninos) de gambás encontradas nos restos dos frutos de $O$. monacantha sugerem que apenas uma espécie de frugívoro utilizou a polpa e sementes como alimento nas áreas estudadas, $D$. aurita, a única espécie do gênero com registro para a Ilha de Santa Catarina, apesar dos diversos estudos já realizados (GRAIPEL et al., 2001; 2006; CÁCERES et al., 2002; 2009; CHEREM et al., 2004; GRAIPEL; SANTOS FILHO, 2006; SALVADOR et al., 2007; 2009; ANTUNES et al., 2009; 2010).

O consumo por gambás deve estar relacionado aos hábitos generalistas da espécie no que se refere ao uso de hábitat e dieta (GRAIPEL et al., 2001; 2006). Na Ilha de Santa Catarina é uma espécie de mamífero comum em vários ambientes, incluindo as restingas, o que em parte é atribuído à ausência de herbívoros de maior porte, alimentando-se de modo oportunístico ou em função da disponibilidade de recursos (GRAIPEL et al., 2006). Nesse sentido, os gambás podem ser os mais importantes dispersores de frutos e sementes de $O$. monacantha em ambientes de restinga.

Os frutos de $O$. monacantha afixados nas plantas foram removidos e transportados por gambás para locais específicos de alimentação, no sub-bosque da restinga arbustiva. Houve um alto consumo dos frutos servidos nestes locais de alimentação. Não se sabe ainda por que os gambás apresentam este comportamento alimentar. Sugere-se que estes marsupiais busquem locais mais seguros para se alimentarem, visto que a maior concentração de plantas de $O$. monacantha ocorre em áreas mais abertas, na vegetação rasteira, próximas da faixa de praia e nos costões rochosos, portanto ambientes mais suscetíveis a predadores. Esse comportamento provavelmente seria vantajoso para 
O. monacantha por proporcionar a multiplicação clonal, a dispersão das sementes, o transporte para locais distantes (colonização) e a quebra da dormência das sementes (endozoocoria). Corroborando esta hipótese, Mandujano et al. (1997) relatam que, o comportamento alimentar do frugívoro pode interferir diretamente na reprodução sexuada de Opuntia rastrera F.A.C. Weber (Cactaceae), por meio da colonização de locais distantes e aumento da variabilidade genética da população.

O processo de dispersão via hidrocoria marítima ainda não havia sido relatado para a família Cactaceae, sendo desconhecida uma hipótese para explicar os mecanismos evolutivos envolvidos na dinâmica dispersiva de $O$. monacantha. As invasões marinhas ("overwash"), que ocorrem com as ressacas causadas pela passagem de tempestades sobre o Oceano Atlântico, possuem um papel primordial nos padrões de remoção de indivíduos ou partes de O. monacantha e na sua posterior deposição nas praias. Castellani e Santos (2005), em estudo sobre a invasão do mar em praias da Ilha de Santa Catarina, inclusive na praia da Galheta, sugerem para Ipomoea pes-caprae (L.) R.Br. (Convolvulaceae) uma avaliação mais integrada da dinâmica de ocupação das populações desta espécie. Estes autores atentam que, devido aos constantes riscos de destruição e reconstrução de seus hábitats, que podem gerar ciclos de remoção e re-colonização populacional, a dispersão marinha garante a colonização de novas áreas. No entanto, a invasão marinha pode, também, reduzir o vigor reprodutivo pela remoção dos ramos férteis, interferir no estabelecimento das sementes e juvenis por meio do aumento da salinidade e a certos graus de soterramento (CASTELLANI; SANTOS, 2005).

Os cladódios e frutos de $O$. monacantha podem flutuar e permanecer viáveis na água do mar por mais de duas semanas. A capacidade de flutuação apresentada por cladódios e frutos da espécie e a tolerância que apresenta pela água do mar indica um potencial para a dispersão marinha destes propágulos a longas distâncias. Ainda que não haja uma explicação adequada que associe uma adaptação na morfologia e fisiologia de cladódios e frutos à dispersão hidrocórica, as modificações adquiridas na morfologia das opúntias (como por exemplo, a reserva de recursos e proteção) e aos ambientes áridos onde habitam, poderiam estar indiretamente ligadas aos processos de dispersão via flutuação. Segundo Hills (2001), cladódios e frutos são protegidos por uma grossa camada de cutina que os protege de fungos, bactérias e da alta incidência luminosa, e por tecidos internos constituídos por grandes células mucilaginosas que podem reter água. Nestas células pode haver, também, a retenção de maiores quantidades de $\mathrm{O}_{2}$ e $\mathrm{CO}_{2}$ (HILLS, 2001).

Os diferentes mecanismos e processos de dispersão de $O$. monacantha podem indicar um relevante acréscimo na diversidade gênica da espécie, tanto na população como entre populações, demonstrando um papel importante no fluxo gênico via propagação vegetativa (cladódios e frutos) e dispersão sexuada (sementes).

\section{Agradecimentos}

Aos dois assessores pelas sugestões e correções. $\mathrm{O}$ primeiro autor foi apoiado com uma bolsa de estudos pela CAPES (Coordenação de Aperfeiçoamento de Pessoal de Nível Superior).

\section{Referências}

ANTUNES, P. C.; CAMPOS, M. A.; OLIVEIRA-SANTOS, L. G. R.; GRAIPEL, M. E. Population dynamics of Akodon montensis (Rodentia, Cricetidae) in the Atlantic forest of Southern Brazil. Mammalian Biology, Jena, v. 75, n. 2, p. 186-190, 2010.

ANTUNES, P. C.; CAMPOS, M. A.; SANTOS, L. G. R.; GRAIPEL, M. E. Population dynamics of Euryoryzomys russatus and Oligoryzomys nigripes (Rodentia, Cricetidae) in an Atlantic forest area, Santa Catarina Island, Southern Brazil. Biotemas, Florianópolis, v. 22, n. 2, p. 137-145, 2009.

ARAÚJO, D. S. D. Vegetations types of sandy coastal plains of tropical Brazil: a first aproximation. In: SEELIGER, U. (Coord.). Coastal plant communities of latin America. Academic Press: New York, 1992. p. 337-347.

ARAÚJO, D. S. D.; LACERDA, L. D. A natureza da restinga. Ciência Hoje, Rio de Janeiro, v. 6, n. 33, p. 42-48, 1987.

CACERES, N. C.; GRAIPEL, M. E.; GHIZONI JUNIOR, I. R. Diet of two marsupials, Lutreolina crassicaudata and Micoureus demerarae, in a coastal Atlantic Forest island of Brazil. Mammalia, Paris, v. 66, n. 3, p. 331-340, 2002.

CACERES, N. C.; PRATES, L. Z.; GHIZONI JUNIOR, I. R.; GRAIPEL, M. E. Frugivory by black-eared opossum Didelphis aurita in the Atlantic Forest of southern Brazil: roles of sex, season and sympatric species. Biotemas, Florianópolis, v. 22, n.3, p. $203-$ 211, 2009. 
CASTELlANI, T. T.; SANTOS, F. A. M. Abundância de ramos reprodutivos e produção de sementes em populações de Ipomoea pes-caprae (L.) R. Br. na Ilha de Santa Catarina, Brasil Acta Botanica Brasilica, Feira de Santana, v. 19, n. 2, p. 251-264, 2005. CASTRO, E. R. de; GALETTI, M. Frugivoria e dispersão de sementes pelo lagarto Teiú Tupinambis merianae (Reptilia: Teiidae). Papéis Avulsos de Zoologia, São Paulo, v. 44, n. 6, p. 91-97, 2004.

CHEREM, J. J.; ALTHOFF, S. L.; SIMOES-LOPES, P. C.; GRAIPEL, M. E. Lista dos mamíferos do estado de Santa Catarina, sul do Brasil. Mastozoologia Neotropical, Tucumán, v. 11, n. 2, p. 151-184, 2004.

DOMÍNGUEZ-DOMÍNGUEZ, L. E.; MORALES-MÁVIL, J. E.; ALBA-LANDA, J. Germinación de semillas de Ficus insipida (Moraceae) defecadas por tucanes (Ramphastos sulfuratus) y monos araña (Atteles geoffroyi). International Journal of Tropical Biology, San José, v. 54, n. 2, p. 387-394, 2006.

EVANS, L. S.; IMSON, G. J.; KIM, J. E. Relationships between numbers of stem segments on longest stems, retention of terminal stem segments and of establishment and detached terminal stem segment for 25 species of Cylindropuntia and Opuntia (Cactaceacae). Journal of the Torrey Botanical Society, Athens, v. 13, n. 13, p. 195-203, 2004.

FALKENBERG, D. B. Aspecto da flora e da vegetação secundária da Restinga de Santa Catarina, sul do Brasil. Insula, Florianópolis, n. 28, p.1-30, 1999.

GRAIPEL, E. M.; CHEREM, J. J.; XIMENEZ, A. Mamíferos terrestres não voadores da Ilha de Santa Catarina, sul do Brasil. Biotemas, Florianópolis, v. 14, n. 2, p. 109-140, 2001.

GRAIPEL, M. E.; SANTOS FILHO, M. Reprodução e dinâmica populacional de Didelphis aurita Wied-Neuwied (Mammalia: Didelphimorphia) em ambiente periurbano na Ilha de Santa Catarina, sul do Brasil. Biotemas, Florianópolis, v. 19, n. 1, p. 65-73, 2006.

GRAIPEL, E. M.; CHEREM, J. J.; MONTEIRO-FILHO, E. L. A.; GLOCK, L. Dinâmica populacional de marsupiais e roedores no Parque Municipal da Lagoa do Peri, Ilha de Santa Catarina, Sul do Brasil. Mastozoología Neotropical, Tucumán, v. 13, n. 1, p. 31-49, 2006.

HILLS, F. S. Anatomia e morfologia. In: FAO/SEBRAE. Agroecologia, cultivo e usos da palma-forrageira. SEBRAE: João Pessoa, 2001. p. 28-35.

IBGE - INSTITUTO BRASILEIRO DE GEOGRAFIA E ESTATÍSTICA. Carta topográfica Florianópolis. 1981a. 1 mapa: 75 x 60cm. Escala: 1.50.000. Rio de Janeiro: IBGE. Disponível em $<$ http://www.ibge.gov.br/mapas_ibge/>. Acesso em: 15 maio 2011. IBGE - INSTITUTO BRASILEIRO DE GEOGRAFIA E ESTATÍSTICA. Carta topográfica Lagoa. 1981b. 1 mapa: 75 x $60 \mathrm{~cm}$. Escala: 1.50.000. Rio de Janeiro: IBGE. Disponível em $<$ http://www.ibge.gov.br/mapas_ibge/>. Acesso em: 15 maio 2011. IBGE - INSTITUTO BRASILEIRO DE GEOGRAFIA E ESTATÍSTICA. Carta Topográfica Paulo Lopes. 1983. 1 mapa: 75 x 60cm. Escala: 1.50 .000 . Rio de Janeiro: IBGE. Disponível em $<$ http://www.ibge.gov.br/mapas_ibge/>. Acesso em: 15 maio 2011. KEDDY, P. A. Population ecology on an environmental gradient: Cakile edentula on a sand dune. Oecologia, Heidelberg, v. 52, p. 348-355, 1982.
KLEIN, A. S.; CITADINI-ZANETTE, V; SANTOS, R. Florística e estrutura comunitária de restinga herbácea no município de Araranguá, Santa Catarina. Biotemas, Florianópolis, v. 20, n. 3, p. 15-26, 2007.

KLEIN, R. M. Aspectos fitofisionômicos da Mata Pluvial da Costa Atlântica do sul do Brasil. Boletim da Sociedade Argentina de Botânica, Córdoba, v. 9, p. 121-140, 1961.

LENZI, M. Biologia reprodutiva de Opuntia monacantha (Willd.) Haw. (Cactaceae) nas restingas da Ilha de Santa Catarina, sul do Brasil. 2008. 95 f. Tese (Doutorado em Ciências) - Universidade Federal de Santa Catarina, Florianópolis. 2008.

MANDUJANO, M. C.; GOLUBOV, J.; MONTAÑA, C. Dormancy and endozoochorous dispersal of Opuntia rastrera seeds in the southern Chihuahuan Desert. Journal of Arid Environments, London, v. 36, p. 259-266, 1997.

MAPA POLÍTICO DO ESTADO DE SANTA CATARINA. 1997. Disponível em $<$ http://www.sc.gov.br/conteudo/santacatarina/ geografia/paginas/mapas.htm>. Acesso em: 10 maio 2011.

PEDRONI, F.; SANCHES, M. Dispersão de sementes de Pereskia aculeata Muller (Cactaceae) num fragmento florestal no sudeste do Brasil. Revista Brasileira de Biologia, São Carlos, v. 57, n. 3, p. 479-486, 1997.

SALVADOR, C. H. O.; GRAIPEL, M. E.; SIMOES-LOPES, P. C. Body size of commom Opossum Didelphis aurita (Didelphimorphia: Didelphidae) on southern brazilian islands. Brazilian Journal of Biology, Rio de Janeiro, v. 68, n. 2, p. 631-637, 2009.

SALVADOR, C. H. O.; PINTO, C. J.; CARVALHO, R.; GRAIPEL, M. E.; SIMOES-LOPES, P. C. Interação parasito-hospedeiro entre ectoparasitos (Ixodida \& Siphonaptera) e gambás Didelphis aurita Wied-Neuwied, 1826 (Mammalia: Didelphimorphia), no continente e em ilhas do litoral de Santa Catarina, Sul do Brasil. Biotemas, Florianópolis, v. 20, n. 4, p. 81-90, 2007.

SATO, T. M.; PASSOS, F. C.; NOGUEIRA, A. C. Frugivoria de morcegos (Mammalia, Chiroptera) em Cecropia pachystachya (Urticaceae) e seus efeitos na germinação das sementes. Papéis Avulsos de Zoologia, São Paulo, v. 48, n. 3, p. 19-26, 2008.

SCHEINVAR, L. Cactáceas. Itajaí: Flora Ilustrada Catarinense, 1985. 384 p.

SCHERER, A.; MARASCHIN-SILVA, F.; BAPTISTA, L. R. M. Florística e estrutura do componente arbóreo de matas de restinga arenosa no Parque Estadual de Itapuã, RS, Brasil. Acta Botanica Brasilica, Feira de Santana, v. 19, n. 4, p. 717-726, 2005.

SCHERER, A.; MARASCHIN-SILVA, F.; BAPTISTA, L. R. M. Padrões de interações mutualísticas entre espécies arbóreas e aves frugívoras em uma comunidade de Restinga no Parque Estadual de Itapuã, RS, Brasil. Acta Botânica Brasílica, Feira de Santana, v. 21, n. 1, p. 203-212, 2007.

SILVA, W. R. Ornitocoria em Cereus peruvianus na Serra do Japi, Estado de São Paulo. Revista Brasileira de Biologia, São Carlos, v. 48 , n. 2, p. 381-389, 1988.

SUGUIO, K. Geologia sedimentar. São Paulo: Edgard Blücher, 2003. 400 p.

ZORTÉA, M.; CHIARELLO, A. G. Observations on the big fruiteating bat, Artibeus lituratus, in an Urban Reserve of South-east Brazil. Mammalia, Paris, v. 58, n. 4, p. 665-670, 1994. 